Goldstein, S. E. (2015). Parental regulation of online behavior and cyber aggression: Adolescents' experiences and perspectives. Cyberpsychology: Journal of Psychosocial Research on Cyberspace, 9(4), article 2. doi: $10.5817 /$ CP2015-4-2

\title{
Parental regulation of online behavior and cyber aggression: Adolescents' experiences and perspectives
}

\author{
Sara E. Goldstein \\ Department of Family and Child Studies, Montclair State University, Montclair, New Jersey, United States
}

\begin{abstract}
The present study examines adolescents' experiences with, and perspectives about, parental regulation of internet-based peer socialization including cyber aggression. Adolescents $(N=$ 110) were surveyed about technology use, electronic device ownership, and the extent to which parents place restrictions on, and/or monitor, their cyber behavior. Adolescents were also asked about their experiences with parental regulation of cyber aggression, and these responses were compared to experiences with other forms of aggressive behavior (relational and overt). Perceptions of legitimacy of parental authority were also compared for online and offline aggression, and for acts typically considered to be within the personal domain. Adolescents believed their online behavior to be primarily unrestricted by parents. Parental regulation of cyber aggression was less prevalent than parental regulation of overt aggression, but greater than parental regulation of relational aggression. Adolescents believed regulation of cyber aggression to be more acceptable than regulation of relational aggression and personal domain behavior.
\end{abstract}

Keywords: Parental monitoring of cyber behavior, adolescent development, cyber aggression

\section{Introduction}

Adolescence is typically characterized by increasing autonomy from direct parental supervision and instruction (McElhaney, Allen, Stephenson, \& Hare, 2009; Zimmer-Gembeck, Ducat, \& Collins, 2011). Teens desire this increased autonomy, and over time believe an increasing number of behaviors to be under their own jurisdiction rather than up to the rules and regulations of their parents or other adults (Darling, Cumsille, \& Martínez, 2008; Smetana \& Asquith, 1994). Autonomy, to some extent at least, is desirable; adolescents who believe their parents to be too intrusive or restrictive are at risk for high susceptibility to peer pressure, associating with delinquent peers, and for engaging in problem behavior (Goldstein, Davis-Kean, \& Eccles, 2005; Keijsers et al., 2012). This being said, there are limits to the benefits of autonomy provision. When too much autonomy and freedom are given to teens, this also places them at an increased risk for problem behaviors and negative peer association (Dishion, Nelson, \& Bullock, 2004; Dishion, Nelson, \& Kavanagh, 2003). Thus, parents must find a place of ever-changing balance between just enough autonomy and freedom to satisfy adolescents' changing needs for selfdirection and independence, without allowing for too much autonomy as to place their children at risk (Goldstein et al., 2005; Tilton-Weaver, Burk, Kerr, \& Stattin, 2013). This is not necessarily an easy balance to find, and it is one that ideally is adjusted with the social and developmental changes of the adolescent and her/his context.

Research on offline peer relationships and social behavior suggests that adolescents who disclose more about their experiences to their parents engage in lower levels of problem behavior and aggression (Kerr, 
Stattin, \& Burk, 2010; Stattin \& Kerr, 2000). Not all social topics, though, are readily discussed with parents. Research also shows that teens believe certain types of offline peer conflict and aggression to be legitimately subject to adult supervision and guidance (e.g., physical aggression), whereas they believe other forms to be outside of adult jurisdiction (e.g., relational aggression; Goldstein \& Tisak, 2006, 2010). With regard to offline aggression, this presents a challenge for prevention and intervention efforts. If teens do not believe a behavior to be within legitimate adult jurisdiction, adults need to be very creative when they attempt to reduce or prevent the particular behavior so that youth believe that the choice whether to desist is under their personal jurisdiction and is outside the boundaries of adult authority (Boxer \& Goldstein, 2012).

Although youth today remain highly invested in offline relationships with their peers, they also are becoming increasingly focused on using technology as a mechanism for peer socialization. Internet-based socialization (e.g., social networking, text messaging) has become a central part of many adolescents' peer relationships. Internet-accessible device use has become ubiquitous among adolescents in the United States, with approximately $95 \%$ indicating that they have an online presence (Madden, Lenhart, Duggan, Cortesi, \& Gasser, 2013). Over $90 \%$ of adolescents have a computer or access to one at home, and $74 \%$ of adolescents report accessing the internet on some type of mobile device such as a smart phone (Madden et al., 2013). Despite this frequent online presence, youth are sometimes reluctant to discuss challenges that they may face in their online activities with their parents (Priebe, Mitchel, \& Finkelhor, 2013). Further, when parent-child discussions about online behavior do occur, many youth experience frustration and uncertainty about parents' positions on their online activities and limit-setting (Haddon, 2015). However, it is not currently known whether youth believe their online social behavior (both friendly interactions and not-so-friendly peer conflicts) to be legitimately subject to parental jurisdiction.

A particular concern when attempting to better understand adolescents' experiences online is their involvement in aggression that has been mediated through technology, referred to in the present paper as cyber aggression. Peer-to-peer aggression taking place via internet-accessible electronic devices has been referred to using a variety of terms, including cyberbullying (e.g., Ybarra, boyd, Korchmaros, \& Oppenheim, 2012), internet aggression (e.g., Werner, Bumpus, \& Rock, 2010), online aggression (e.g., Law, Shapka, \& Olsen, 2010), and cyber aggression (e.g., Schoffstall \& Cohen, 2011). Typically the term used in the individual study depends on the specific aspects of measurement, whether it was persistent and power-related aggression occurring over time (as in the case of bullying) or a focus on single episodes of perpetration, although this is not always the case. This lack of consistency in terminology can be rather confusing. There is inconsistency in the literature regarding operational definitions of cyber aggression and cyber bullying. In the aggression literature (primarily focusing on aggression occurring offline), there is a clear distinction between aggressive behavior and bullying, although the constructs do reflect overlapping (but not identical) behaviors (e.g., Boxer, Terranova, Savoy, \& Goldstein, 2008; Olweus, 1978; Olweus \& Limber, 2010). Bullying implies a repeated, frequent record of perpetrating aggression against an individual where there is a power imbalance between the victim and the perpetrator. Thus, all aggressive behavior does not constitute bullying, although all bullying does involve aggression. Although this is a clear distinction, given the relatively new emergence of cyber aggression and cyber bullying, it is beneficial to scan the literature for a variety of related terms when summarizing the literature. The decision to use the term "cyber aggression" rather than "cyber bullying" in the present paper was made because the aggressive incidences depicted in the current study (and elsewhere, even when the term cyber bullying is used) are not necessarily examples of bullying, as it is typically defined in the literature on youth aggression and bullying (Boxer et al., 2008; Olweus, 1978; Olweus \& Limber, 2010).

Emerging and consistent research over the past decade (using a variety of terms for aggression that is enacted using internet-accessible electronic devices) has shown cyber aggression to be a major concern for youth development. Adolescents who are victimized by cyber aggression are at an increased risk for a variety of psychosocial challenges including low self-esteem (Patchin \& Hinduja, 2010), suicidal thoughts and behaviors (Hinduja \& Patchin, 2010), decreased school attachment and lower school performance (Schneider, O’Donnell, Stueve, \& Coulter, 2012), depressive symptomology (Klomek, Marrocco, Kleinman, Schonfeld, \& Gould, 2008), and victimization in offline contexts (Ybarra \& Mitchell, 2004). Clearly, cyber aggression has emerged as an issue of significant concern for youth development.

Given the deleterious implications of cyber aggression, it is critically important to identify the best ways in which parents, educators, mental health care workers, and other community agents can work to prevent and intervene upon it. Parents in particular can play an key role in discussing cyber behavior and providing clear and specific boundaries for appropriate and inappropriate cyber behavior. Compared to 
friends and teachers, adolescents report that parents are the most frequent agents mediating their online behavior (Wright, 2015). There is growing evidence that parental mediation of youth online behavior is associated with lower levels of victimization by cyber aggression (Seiler \& Navarro, 2014), although some data suggest that this link may be stronger for boys than for girls (Mesch, 2009; Navarro \& Jasinski, 2013). There are still many questions remaining, however, about ways in which parents establish such boundaries for their children. Previous research suggests that parents typically provide and maintain clear rules and regulations about overtly aggressive behavior (occurring offline) such as hitting and pushing, and that children and adolescents generally accept parental jurisdiction over these types of infractions (Tisak, 1995; Tisak, Tisak, \& Goldstein, 2006; Turiel, 2006). In contrast, youth are less accepting of parental jurisdiction over other forms of offline aggressive behavior, such as relational aggression (aggressive behavior that uses social relationships as the mechanism for harm; Goldstein \& Tisak, 2006, 2010). Parental behavior likely contributes to these beliefs. For example, parents are less likely to develop and enforce specific rules about relational aggression, and are less restrictive in their disciplinary action for relational aggression, as compared to physical aggression (Goldstein \& Boxer, 2013; Valles \& Knutson, 2008). Mothers of young children also report being less likely to intervene during an incident of relational versus physical aggression, and also are less upset by relational aggression as compared to physical aggression (Werner, Senich, \& Przepyszny, 2006).

This lack of clear and specific socialization about relational aggression places youth at risk for challenges, as relational aggression can be quite socially sophisticated and confusing to navigate. Cyber aggression, similar to relational aggression, can also involve a high degree of social sophistication and awareness, and can be quite perplexing for victims and perpetrators alike. Without the benefit of direct in-person communication (such as facial expressions, body language, and tone of voice), many ambiguities may arise in youths' interpretations of social interactions that occur online. Further, cyber aggression can occur virtually in any place, and at any time (anywhere that a youth has a cell phone or other portable internetaccessible electronic device) and is not confined to the typical boundaries of a school day or other face-toface social events. Other unique features of cyber communication become a factor as well, including the sometimes unknown identity of a perpetrator as is seen in offline indirect aggression (Björkqvist, Lagerspetz, \& Kaukiainen, 1992). If youth do not believe that parental jurisdiction over cyber aggression (and over online socialization in general) is acceptable, it may be difficult for parents to create and implement straightforward and clear guidelines.

Based on the literature reviewed above, the present study has three goals. The first goal is to understand better adolescents' uses of internet-accessible electronic media, and their perceptions of, and experiences with, parental limitations and monitoring of its use. Second, it is of interest to examine adolescents' perceptions of the extent to which parents regulate their cyber aggression, in comparison to other forms of offline aggressive behavior. The third goal is to assess adolescents' prescriptive beliefs about parental jurisdiction over internet use and cyber aggressive behavior. Do adolescents think that parents should monitor and regulate their cyber aggressive behavior, or do they think that cyber aggression is a personal behavior that should be up to the adolescents themselves to regulate?

Several hypotheses for the current study were made. First, with regard to electronic media use, participating adolescents were expected to be frequent and consistent users of the internet and associated peer socialization platforms. Second, in terms of parental limit setting and monitoring of electronic media use, because the adolescents in the current study were in the middle adolescent age range, and because internet peer socialization may be perceived by parents to be similar to other forms offline peer socialization (and thus a behavior that parents perceive as legitimacy subject to parental authority, Smetana \& Asquith, 1994), it was expected that parents would exert a mid-level of control over their children's internet behavior. Third, in terms of parental jurisdiction over cyber aggression specifically, because cyber aggression shares features with relational aggression (as noted above), it was expected that parents would exert a level of control over it that was less restrictive than for overt aggression. However, since the "harmful" aspect of cyber aggression is more concrete in some ways than the "harmful" aspect of relational aggression (e.g., a fabricated webpage that spreads a rumor about somebody is tangible, whereas a verbal rumor is intangible albeit still hurtful), it was expected that parents would exert greater authority over cyber aggression as compared to relational aggression.

The fourth and final hypotheses pertained to adolescents' prescriptive beliefs about parental jurisdiction over cyber aggression. Because cyber aggression may be seen as an unambiguous way to harm a peer (whereas relational aggression can sometimes be construed as a "personal choice" in terms of friendship termination or companion choice; Goldstein \& Tisak, 2006, 2010), it was expected to be seen by adolescents as a relatively legitimate area for parents to regulate, in comparison to relational aggression 
as well as social behaviors that fall under the personal domain (e.g., personal grooming and developing a new friendship). However, adolescents were expected to be less accepting of parental jurisdiction over cyber aggression as compared to overt aggression, because of the "gray" area of relationship navigation (which is a personal issue) that occurs in online communications that can sometimes turn mean (and thus can evolve into cyber aggression).

\section{Method}

\section{Participants}

Participants were 110 adolescents from two public, suburban high schools located in the northeastern United States $(M=17.05$ years, $S D=0.60)$. The schools were from a single high school district; all students enrolled in the schools' psychology classes were offered the opportunity to participate $(N=131)$. The overall participation rate from these classes $(N=5)$ was $83.9 \%$; all non-participation was due to student absences or to parental consent forms that were not returned. Participants were primarily White/European American (87.2\%) and had parents who had at least a 4-year college degree (70.6\%). In terms of gender, 70 participants identified as female and 24 identified as male; 16 students elected not to specify gender on the survey. All students were either in the eleventh $(19 \%)$ or twelfth $(81 \%)$ grades.

\section{Measures}

Questions focused on adolescents' social experiences (both online and offline), the extent to which their parents regulated these social experiences, and their beliefs about parental regulation. Specifics about the items focused on in the present manuscript are listed below.

Electronic device use. Participants were asked whether they owned a computer ( 1 question) and a cell phone (1 question). For these questions, participants responded with either no (0) or yes (1). Participants also reported on how many hours per day they used a computer (1 question) and or a cell phone (1 question). Finally, participants noted the frequency with which they used the following communication mechanisms when they were not actually with their friends (based on Werner et al., 2010): email, blogging, chat rooms, text messaging, social networking, and massively multiplayer online games (MMO/MMOG). Each of this last group of questions was answered on a scale of 1 (never) through 6 (20 times or more); participants were asked to consider the last 30 days.

Parental limits placed on electronic device use. Participants reported whether their parents "place any limits" on how much time they spend on their computer (1 question) and their cell phone (1 question). Participants were also asked whether the computer that they use most has "software that blocks pop up ads or spam" and whether it "has software that filters, blocks, or monitors internet use" (Ybarra, Finkelhor, Mitchell, \& Wolak, 2009). Identical questions were asked about cell phones. For each question, participants could answer either "No," "Yes," "I don't know," or "I don't have the device."

Prescriptive beliefs about parental limits on electronic device use. Youth were asked to indicate whether parents should "place any limits" on how much time they spend on their computer (1 question) and their cell phone (1 question). Response options were "No," "Yes," "I don't know," or "I don't have the device."

Parental rules for aggressive behavior. Youth were asked if their parents had rules about three types of aggressive behavior, cyber (3 questions, $a=.92$ ), overt ( 3 questions, $a=.81$ ), and relational (3 questions, $a=.87)$. For each question, participants were presented with a behavior and then were asked to respond with either no $(0)$ or yes (1) to indicate whether their parents had rules about that particular behavior. For cyber aggression, the items were: sending a mean text message, making up a mean fake webpage, and making up a story about another kid and spreading it around online. For offline overt aggression, the behaviors were hitting, shoving, and threatening to beat up another kid. Finally, for offline relational aggression the items were keeping someone out of an activity, talking about somebody behind their back, and making up a story about another kid and spreading it around school. To compute each scale, scores were averaged across items for each type of aggressive behavior.

Prescriptive beliefs about parental rules for aggressive behavior. To measure adolescents' beliefs about whether parents should have rules about aggressive behavior, participants were asked to indicate the extent to which they believed that parents should regulate their cyber ( 3 items, $a=.90$ ), overt ( 3 
items, $a=.87$ ), and relational ( 3 items, $a=.88$ ) aggressive behavior. For comparison, participants were also asked to indicate whether they believed that parents should regulate their personal behaviors (i.e., behaviors that are typically considered by youth to be under their own individual jurisdiction, e.g., Smetana, 1988; Tisak, 1986; 2 items, $a=.73$ ). For prescriptive beliefs about rules for aggression, identical stems to the rule presence questions were used (these are listed above). With regard to prescriptive beliefs about rules for personal behaviors, youth evaluated the extent to which they believed that parents should have rules about their child (1) getting a new hairstyle, and (2) making a new friend. For all items, scores ranged from 0 (No! Parents definitely should not have a rule) through 3 (Yes! Parents definitely should have a rule). Questions were inspired by previous work focusing on adolescents' conceptions of parental authority over non-cyber forms of aggression (Goldstein \& Tisak, 2010). Total scores for each scale were computed by averaging items across each type of social behavior.

\section{Procedures}

Data were collected at the participants' schools, in their classrooms, during their regularly scheduled class times. The researcher visited each of the 5 participating classes approximately 2 weeks prior to data collection, to describe the study and distribute parent consent forms. Students were instructed to bring the forms home to their parents, and to then return them to school after a parent or guardian had reviewed and signed the form. Teachers collected the forms over the next several days. On the day of data collection, all students who had returned the signed, affirmative parent consent forms and/or who were 18 years old or older were eligible to participate in the survey. All eligible students participated. The researcher distributed the surveys (which were in offline/paper-and-pencil format), and students completed the surveys independently. Each student completed one survey. The researcher was available to answer questions. The full survey took approximately 20-30 minutes to complete. After students had completed the survey, they were given a small thank-you gift (a pen, pencil, or other small school supply item).

\section{Results}

\section{Adolescents' Internet-Accessible Electronic Device Use}

Descriptive statistics were calculated to better understand adolescents' electronic device use. $97.3 \%$ of the sample reported owning a computer, and $100 \%$ of the sample indicated that they owned a cell phone. Participants reported spending an average of 4.08 hours per day on their computers $(S D=4.70)$, combined with an average of 7.56 hours per day on their cell phones $(S D=6.91)$. With regard to the virtual mechanism of peer socialization (which could take place on any device that had internet access), text messaging and social networking were the two most common (with $91.7 \%$ and $55.5 \%$ saying that they have used these mechanisms 20 times or more during the past month, respectively). Table 1 presents additional information about the frequency of peer socialization via different virtual platforms.

Table 1. Peer Socialization via Virtual Mechanisms during Past 30 Days (Percentages).

\begin{tabular}{lcccc}
\hline Type of virtual mechanism & $\begin{array}{c}\text { Never } \\
\text { (0 times) }\end{array}$ & $\begin{array}{c}\text { Occasional } \\
\text { (1-5 times) }\end{array}$ & $\begin{array}{c}\text { Frequent } \\
\mathbf{( 6 - 1 9} \text { times) }\end{array}$ & $\begin{array}{c}\text { Very frequent } \\
\text { (20 times or more) }\end{array}$ \\
\hline Email & 10.0 & 29.1 & 27.3 & 33.6 \\
Blog & 66.4 & 17.3 & 8.1 & 8.2 \\
Chat room & 85.5 & 10.9 & 1.8 & 1.8 \\
Text messaging & .9 & 3.6 & 3.7 & 91.7 \\
Social networking & 14.5 & 10.0 & 20.0 & 55.5 \\
MMOG & 80.0 & 10.9 & 6.3 & 2.7 \\
\hline
\end{tabular}

Note: MMOG = Massively multiplayer online games.

\section{Parental Limits for Electronic Device Use}

Next, descriptive statistics were calculated to better understand the ways in which parents attempted to limit and/or monitor their adolescents' electronic device use. As noted on Table 2, very few youth believed that their parents placed any limits on the amount of time that they spent on their computer (5.6\%) or on their cellphone (3.6\%). Further, the majority of the sample believed that their computers $(53.6 \%)$ and 
their cellphones $(81.7 \%)$ did not have software installed to filter, block, or monitor internet use. In terms of blocking pop up advertisement or spam, $70.9 \%$ of participants indicated that their computers had blocking software; whereas only $22.7 \%$ said that blocking software was on their cellphones. In terms of direct parental monitoring of internet use, $91.8 \%$ of the sample indicated that their parents did not keep track of their internet use on the computer, and $85.3 \%$ reported that their parents did not keep track of their internet use on the cell phone.

Table 2. Parental Limits of Internet Use on the Computer and Cell Phone (Percentages).

\begin{tabular}{lcccc}
\hline Type of limit setting/ monitoring & Yes & No & $\begin{array}{c}\text { Adolescent does } \\
\text { not know }\end{array}$ & $\begin{array}{c}\text { Adolescent does not } \\
\text { have device }\end{array}$ \\
\hline Parents place a limit on computer time & 5.6 & 94.4 & -- & -- \\
Parents place a limit on cell phone time & 3.6 & 96.4 & -- & -- \\
$\begin{array}{l}\text { Parents keep track of internet use on the computer } \\
\text { Parents keep track of internet use on the cell phone }\end{array}$ & 2.7 & 91.8 & 4.5 & .9 \\
$\begin{array}{l}\text { Computer has software that blocks, filters, or } \\
\text { monitors internet use }\end{array}$ & 32.7 & 53.6 & 12.7 &.- \\
$\begin{array}{l}\text { Cell phone has software that blocks, filters, or } \\
\text { monitors internet use }\end{array}$ & 11.0 & 81.7 & 7.3 & -9 \\
$\begin{array}{l}\text { Computer has software that blocks pop up adds or } \\
\text { spam }\end{array}$ & 70.9 & 14.5 & 13.6 & .9 \\
$\begin{array}{l}\text { Cell phone has software that blocks pop up adds or } \\
\text { spam }\end{array}$ & 22.7 & 60.9 & 16.4 & -- \\
\hline
\end{tabular}

\section{Prescriptive Beliefs about Parental Limits for Electronic Device Use}

Descriptive statistics were computed regarding adolescents' beliefs about whether parents should place limits on their electronic device use. Regarding computer use, 59.6\% of the adolescents indicated that their parents should not keep track of their internet use $(26.6 \%$ and $13.8 \%$ said that they should keep track, or that they didn't know, respectively). In terms of cell phone use, $62.7 \%$ of the sample thought that their parents should not keep track of their internet use (whereas $23.6 \%$ and $13.6 \%$ believed that they should keep track, or that they didn't know, respectively).

\section{Parental Rules for Aggressive Behavior: Cyber Versus Non-Cyber Aggression}

The goal of the next analysis was to explore the ways in which parents attempt to regulate their adolescents' online behavior, and to compare it to attempts to regulate offline behavior. Thus, parental rules for cyber aggression were compared to parental rules for overt and relational aggression. Based on the well-established gender differences in non-cyber aggression and aggression-supporting cognitions (e.g., Card, Stucky, Sawalani, \& Little, 2008), gender differences were also tested in the analysis. Thus, a 3 (aggression type) $\times 2$ (gender) repeated measures ANOVA was conducted to assess the presence of specific rules prohibiting different forms of aggressive behavior. Aggression type was the repeated measure. There was a significant main effect for aggression type $F(2,176)=21.91, p<.001$; partial $\eta^{2}=$ .20. Adolescents reported significantly more rules about overt aggression $(M=0.56, S D=0.43)$, as compared to either relational $(M=0.37, S D=0.42 ; p<.001)$ or cyber $(M=0.44, S D=0.47 ; p<.001)$ aggression. Moreover, rules about cyber aggression were more likely than rules about relational aggression $(p<.05)$. There was also a significant main effect for gender $F(1,88)=68.72, p<.01 ;$ partial $\eta^{2}=.08$. Girls reported that their parents were more likely to have rules overall, as compared to boys.

\section{Adolescents' Beliefs about Parental Rules}

The focus of the next analysis was to investigate adolescents' beliefs about the legitimacy of parental rules for cyber aggression. Beliefs about parental rules for cyber aggression were compared to beliefs 
regarding parental rules for overt and relational aggression, as well as for "personal" behaviors. Gender differences in conceptions of parental authority were also tested. Thus, a 4 (social behavior type) X 2 (gender) ANOVA for repeated measures was conducted. Social behavior type was the repeated measure. There was a significant main effect for social behavior type, $F(3,261)=342.16, p<.001$; partial $\eta^{2}=$ .88. There was also a significant main effect for gender, $F(1,87)=612.49$, partial $\eta^{2}=.12$ which was qualified by a significant interaction between social behavior type and gender, $F(3,361)=10.61, p<$ .001 ; partial $\eta^{2}=.20$. Results indicate that adolescents believed parental rules about cyber aggression $(M$ $=2.30, S D=0.83)$ to be more acceptable, as compared to rules about relational aggression $(M=2.05$, $S D=0.76, p<.001)$ or personal behaviors $(M=0.14, S D=0.42, p<.001)$. Rules about relational aggression were less acceptable as compared to rules about overt aggression $(M=2.29, S D=0.71, p<$ $.01)$, but more acceptable than rules about personal behavior $(p<.001)$. Additionally, rules about personal behavior were considered to be significantly less acceptable than rules about cyber $(p<.001)$, relational $(p<.001)$, and overt aggression $(p<.001)$. Regarding the significant gender $\mathrm{x}$ social behavior type interaction, follow up analyses indicated that girls were more supportive of rules prohibiting aggression ( $p s<.01)$, but there were no gender differences for personal behavior [Boys: cyber aggression $(M=1.85, S D=0.94)$, relational aggression $(M=1.67, S D=0.87)$, overt aggression $(M=$ $1.80, S D=0.75)$, personal behavior $(M=0.19, S D=0.64)$; Girls: cyber aggression $(M=2.47, S D=$ $0.72)$, relational aggression $(M=2.21, S D=0.67)$, overt aggression $(M=2.47, S D=0.61)$, personal behavior $(M=0.12, S D=0.31)]$.

\section{Discussion}

The present study examined adolescents' experiences with, and beliefs about, parental jurisdiction over their online peer socialization. Participants reported on their technology use and their online peer socialization habits, and the extent to which their parents regulated general technology use and cyber aggression. Adolescents also provided their opinions about the extent to which they thought that parents should regulate technology use and cyber aggressive behavior.

Consistent with the first hypothesis, adolescents in the present sample were frequent cell phone and computer users; using their cell phones approximately 7.5 hours per day on average and using their computers an average of just over 4 hours per day. Participants in the current study also reported being regular users of a variety of internet-based platforms to socialize with their peers. Specifically, text messaging and using social networking sites were the most frequently used methods, with the majority of participants reporting almost daily use of these mechanisms. These numbers are consistent with recent nationally representative reports of adolescent media usage (Madden et al., 2013), and highlight the ubiquitous nature of "media saturation" (Brown \& Bobkowski, 2011) in today's youth. Taken together with research showing the potential protective effect of parental mediation of internet use on cyber victimization (Mesch, 2009; Navarro \& Jasinski, 2013; Seiler \& Navarro, 2014) these results also underscore why it is so critical to understand the best ways for parents to promote healthy online behavior among their children.

Despite adolescents' frequent use of computers and cell phones, and the internet-based peer socialization available to them on these devices, parents of the participants in the present sample did not seem to be providing much structure with regard to their use. This was inconsistent with the second hypothesis, which was that parents would exert a mid-level (i.e., moderate) control and structure over their children's internet use. The majority of participants in the present study did not believe that their parents established limits with regard to the time that they spent on their electronic devices, nor did they believe that restrictive/monitoring software had been installed on their devices. Adolescents in the present sample perceive that they are essentially being left to self-regulate with regard to their electronics use. The implications of this autonomy are unclear. Autonomy with regard to activity selection and social relationships are important developmental goals to achieve, and by mid-adolescence it is typical for parents to allow for increased social and behavioral autonomy, while still exerting some control (McElhaney et al., 2009; Zimmer-Gembeck et al., 2011). It is not clear based on the present data whether parents are allowing for autonomy for online behaviors because of perceptions of the developmental needs of their children, or because they are not aware of how to engage in supervision for online behaviors due to a generational digital divide or potentially due to their status as digital "immigrants" (e.g., Prensky, 2001a; 2001b). For example, one study found that when parents themselves spent more time on the internet, they were more concerned about establishing internet rules for their children (Lou, Shih, Liu, Guo, \& Tseng, 2010). Alternatively, perhaps the lack of parental involvement may be due to perceived obstacles that parents face with regard to regulating their children's internet use, such as not being present in the home at the time of online activity or in an attempt to avoid a 
disagreement (Talves \& Kalmus, 2015). Nonetheless, given the potential for harm on the internet, both in terms of peer relationship challenges and other dangers such as privacy violations or predatory adults), a lack of parental limit setting may be a safety concern, even in youth in this age range.

Despite perceptions of parental leniency, many of the adolescents in the current sample disagreed with their parents' lack of supervision and limitations regarding their cell phone and computer use. Approximately one fourth of the sample believed that their parents should keep track of their technology use, and approximately $10 \%$ more were unsure of whether parents should monitor. Perhaps the adolescents who believed that increased supervision would be ideal had a more realistic idea of the possibilities of what could happen online. Alternatively, the participants who believed that parents should supervise more may also not be ready for behavioral and social autonomy across domains, not just in terms of their online behavior. The present data do not allow for testing of these speculations; however, it will be interesting for future research to explore further the reasons why some adolescents prefer increased parental supervision regarding their technology use.

With regard to parental regulation over cyber aggression, adolescents and their parents seemed to have compatible ideas. Adolescents perceived their physical aggression and cyber aggression to be regulated by their parents (although physical aggression was relatively more regulated), compared to relational aggression. This provides partial support for the third hypothesis, that both cyber aggression and physical aggression would be relatively regulated as compared to relational aggression. Adolescents generally agreed with their parents' decisions about this. Consistent with the fourth hypothesis, youth believed that cyber aggression was something legitimately under their parents' jurisdiction, similar to physical aggression. In contrast, adolescents in the present sample believed relational aggression and personal behaviors to be less acceptable for parents to regulate. These results add to previous research on parental regulation of aggressive behavior, by expanding the literature to include cyber aggression and comparing adolescents' perspectives on regulation of offline versus online aggression. Past research (focusing on offline aggression) showed parental socialization for relational versus physical aggression to be different. In comparison to overt forms of aggression, parents are relatively less upset about their children's relational aggression, and fewer explicit rules and regulations are established for relationally aggressive behavior (Goldstein \& Boxer, 2013; Valles \& Knutson, 2008; Werner et al., 2006). These beliefs about relational aggression are reflected in adolescents' thinking about it, in that they perceive it to be more acceptable, and less legitimately subject to parental authority, as compared to physical aggression (Goldstein \& Tisak, 2006, 2010). The current results provide further evidence of these trends, and also deliver preliminary evidence of the ways in which parents regulate cyber aggression. Adolescents in the present study believed their parents to be exerting a moderate amount of limit-setting about cyber aggressive behavior, although not as much as for overtly aggressive behavior. In general, participants in the present study were okay with this perceived show of parental jurisdiction. This is preliminary evidence that adolescents may be evaluating cyber aggression as a moral issue, in that adolescents believe that rules and regulations limiting or prohibiting its enactment are acceptable. Additional research, however, is needed to further clarify why adolescents believe that parental jurisdiction over cyber aggression is relatively acceptable.

Gender differences also emerged with regard to parental regulation of aggressive behavior, and prescriptive beliefs about parental jurisdiction about aggression. Girls, as compared to boys, perceived their parents to be relatively controlling. They also held beliefs that were relatively accepting of this parental jurisdiction. These findings are consistent with previous research indicating that parents are relatively more restrictive and controlling of their daughters' social behavior, as compared to their sons' social behavior (e.g., Dishion \& McMahon, 1998; Pomerantz \& Ruble, 1998). Although a few studies show no gender differences in parental monitoring of online behaviors (Mitchell, Finkelhor, \& Wolak, 2005; Wright, 2015), other research pertaining to online behavior show that gender differences in parent-child interactions might also vary by culture (Talves \& Kalmus, 2015), which was a variable not explored in the present study. Thus, these results provide initial support for the idea that online behavior may be differentially socialized in boys versus girls. As is the case with the implications of other ways in which parents differentially socialize their sons and daughters, this presents a challenging situation for girls and boys alike. From one perspective, girls are receiving the message that they are less capable of autonomy then are their male peers. From another perspective, boys are receiving fewer benefits of parental supervision with regard to complex social behaviors, as compared to their female peers. It is interesting to note, however, that despite these gender differences, the general pattern of findings was the same for girls and boys alike, in terms of their evaluations for cyber aggression versus other forms of aggression and social behavior. It is not clear why gender differences were found in the present study, but not in previous research. Perhaps it is because the age of adolescents in the present sample was slightly higher 
than in the studies reporting no gender differences, or perhaps it may be due to other factors not measured. Nonetheless, additional research exploring gender differences in parental mediation of adolescents' online behavior is warranted.

The finding that adolescents are relatively comfortable with parental jurisdiction over cyber aggression has implications for prevention and intervention. Because adolescents are generally accepting of parental authority over cyber aggression, this opens the door for receptivity to frank, open parent-child discussions about its implications and consequence. Parents should take advantage of this opportunity, and should approach conversation about this topic on a regular basis. Taken together with the finding that many adolescents in the present sample were open to increased monitoring of their internet and cell phone use, it seems as though parents of high-school aged children may still have the "green light" in terms of scaffolding their adolescents' online presence. This is not to say that parents should proceed in an overly intrusive manner, as this is clearly not ideal for parent-child relationships or adolescent outcomes (Goldstein et al., 2005, Keijsers et al., 2012). Rather, parents should establish an environment of open communication, where the adolescent is encouraged to take the lead in terms of disclosure of their behaviors and experiences with cyber aggression. Research on offline peer experiences suggests that this is an ideal approach for facilitating parental knowledge and positive adolescent development (Kerr et al., 2010; Stattin \& Kerr, 2000).

Finally, several limitations of the current study should be taken into consideration when interpreting the results. First, the present study relied entirely on self-report data. While adolescents themselves are arguably the best reporters of their judgments about parental authority, it would be interesting for future research to also include parental reports of ways in which they try to/believe that they monitor/limit their children's technology use and cyber aggression. Second, this sample was primarily white and middle class, and had relatively well educated parents. Although these characteristics mirror the demographics of the participating schools, it is critical that future research explore similar topics with a racially and socioeconomically diverse sample. Finally, adolescents in the present study were in the middle adolescent age range (16-18 year olds, high school juniors and seniors) and were sampled from psychology classes within the high school. Although psychology classes were open to all students, there may have been some sampling bias based on those who elected to take this particular class versus another type of class. Thus, the current findings may not generalize to younger children and adolescents, or to older youth, or to youth who would not want to take a psychology course in high school. Given the relatively modest sample size of the current study, this investigation could be conceptualized as exploratory in nature, and an emphasis for future research on this topic should be to focus on larger samples including increased contextual and demographic diversity.

Despite these limitations, the findings from the present study represent a preliminary step in understanding better the ways in which parents socialize their adolescents' online behaviors and cyber aggression. Moreover, the current results provide preliminary insight as to adolescents' perspectives on how parents should provide structure for their online experiences. Adolescents in the present sample were split in terms of their beliefs about whether parents should set boundaries and limits on their online socializing. When it came to cyber aggression in particular, though, adolescents believed parental jurisdiction to be relatively acceptable. Parents may wish to take advantage of this in ways that help to protect and educate their adolescents, albeit in a way that does not feel too intrusive (Goldstein et al., 2005). For example, parents should set clear expectations about acceptable and non-acceptable online behavior, and should let their children know that they are available to talk about any challenges that they are experiencing whether they occur online or offline. Parents should become aware of school-based policies and procedures regarding cyber aggression, and should educate their adolescents about these policies. Providing their adolescents with the contact information of a school-based contact point to seek out for assistance might be beneficial as well. Finally, parents should stay up-to-date on the social media outlets that their adolescents are using, and they should regularly engage their adolescents in discussions about cyber aggression and technology use. It is possible that parents may have less knowledge about various aspects of the online world, as compared to their children, but this does not mean that they should remain uninformed about their whereabouts online. 


\section{References}

Björkqvist, K., Lagerspetz, K. M. J., \& Kaukiainen, A. (1992). Do girls manipulate and boys fight? Aggressive Behavior, 18, 117-127. http://dx.doi.org/10.1002/1098-2337(1992)18:2<117::AIDAB2480180205>3.0.CO;2-3

Boxer, P., \& Goldstein, S. E. (2012). Treating juvenile offenders: Best practices and emerging critical issues. In E. Grigorenko (Ed.), Handbook of juvenile forensic psychology and psychiatry (pp. 323-340). New York: Springer.

Boxer, P., Terranova, A. M., Savoy, S. C., \& Goldstein, S. E. (2008). Developmental issues in the prevention of aggression and violence in school. In T. Miller (Ed.), School violence and primary prevention (pp. 277-294). New York: Springer.

Brown, J., \& Bobkowski, P. (2011). Older and newer media: Patterns of use and effects on adolescents' health and well-being. Journal of Research on Adolescence, 21, 95-113.

http://dx.doi.org/10.1111/j.1532-7795.2010.00717.x

Card, N. A., Stucky, B. D., Sawalani, G. M., \& Little, T. D. (2008). Direct and indirect aggression during childhood and adolescence: A meta-analytic review of gender differences, intercorrelations, and relations to maladjustment. Child Development, 79, 1185-1229. http://dx.doi.org/10.1111/j.1467-

8624.2008.01184.x

Darling, N., Cumsille, P., \& Martínez, M. L. (2008). Individual differences in adolescents' beliefs about the legitimacy of parental authority and their own obligation to obey: A longitudinal investigation. Child Development, 79, 1103-1118. http://dx.doi.org/10.1111/j.1467-8624.2008.01178.x

Dishion, T. J., \& McMahon, R. J. (1998). Parental monitoring and the prevention of child and adolescent problem behavior: A conceptual and empirical formulation. Clinical Child and Family Psychology Review, 1, 61-75. http://dx.doi.org/10.1023/A:1021800432380

Dishion, T. J., Nelson, S. E., \& Bullock, B. M. (2004). Premature adolescent autonomy: Parent disengagement and deviant peer process in the amplification of problem behavior. Journal of Adolescence, 27, 515-530. http://dx.doi.org/10.1016/j.adolescence.2004.06.005

Dishion, T. J., Nelson, S. E., \& Kavanagh, K. (2003). The family check-up with high-risk young adolescents: Preventing early-onset substance use by parent monitoring. Behavior Therapy, 34, 553-571. http://dx.doi.org/10.1016/S0005-7894(03)80035-7

Goldstein, S. E., Davis-Kean, P. E., \& Eccles, J. S. (2005). Parents, peers, and problem behavior: A longitudinal investigation of the impact of relationship perceptions and characteristics on the development of adolescent problem behavior. Developmental Psychology, 41, 401-413.

http://dx.doi.org/10.1037/0012-1649.41.2.401

Goldstein, S. E., \& Boxer, P. (2013). Parenting practices and the early socialization of relational aggression. Early Child Development and Care, 183, 1559-1575.

http://dx.doi.org/10.1080/03004430.2012.738200

Goldstein, S. E., \& Tisak, M. S. (2006). Early adolescents' conceptions of parental and friend authority over relational aggression. Journal of Early Adolescence, 26, 344-364.

http://dx.doi.org/10.1177/0272431606288552

Goldstein, S. E., \& Tisak, M. S. (2010). Early adolescents' social reasoning about relational aggression. Journal of Child and Family Studies, 19, 471-482. http://dx.doi.org/10.1007/s10826-009-9319-1

Haddon, L. (2015). Children's critical evaluation of parental mediation. Cyberpsychology: Journal of Psychosocial Research on Cyberspace, 9(1), article 2. http://dx.doi.org/10.5817/CP2015-1-2 
Hinduja, S., \& Patchin, J. W. (2010). Bullying, cyberbullying, and suicide. Archives Of Suicide Research, 14, 206-221. http://dx.doi.org/10.1080/13811118.2010.494133

Keijsers, L., Branje, S., Hawk, S. T., Schwartz, S. J., Frijns, T., Koot, H. M., . . Meeus, W. (2012).

Forbidden friends as forbidden fruit: Parental supervision of friendships, contact with deviant peers, and adolescent delinquency. Child Development, 83, 651-666. http://dx.doi.org/10.1111/j.1467-

8624.2011.01701.x

Kerr, M., Stattin, H., \& Burk, W. J. (2010). A reinterpretation of parental monitoring in longitudinal perspective. Journal of Research on Adolescence, 20, 39-64. http://dx.doi.org/10.1111/j.15327795.2009.00623.x

Klomek, A. B., Marrocco, F., Kleinman, M., Schonfeld, I. S., \& Gould, M. S. (2008). Peer victimization, depression, and suicidality in adolescents. Suicide And Life-Threatening Behavior, 38, 166-180.

http://dx.doi.org/10.1521/suli.2008.38.2.166

Law, D. M., Shapka, J. D., \& Olson, B. F. (2010). To control or not to control? Parenting behaviors and adolescent online aggression. Computers in Human Behavior, 26, 1651-1656.

http://dx.doi.org/10.1016/j.chb.2010.06.013

Lou, S., Shih, R., Liu, H., Guo, Y., \& Tseng, K. (2010). The influences of the sixth graders' parents' internet literacy and parenting style on internet parenting. The Turkish Online Journal of Educational Technology, 9, 173-184.

Madden, M., Lenhart, A., Duggan, M., Cortesi, S., \& Gasser, U. (2013). Teens and technology 2013. Washington, DC: Pew Internet \& American Life Project.

McElhaney, K., Allen, J., Stephenson, J., \& Hare, A. (2009). Attachment and autonomy during adolescence. In R. M. Lerner \& L. Steinberg (Eds.), Handbook of adolescent psychology: Vol. 1. Individual bases of adolescent development (3rd ed., pp. 358-403). Hoboken, NJ: John Wiley \& Sons Inc.

Mesch, G. S. (2009). Parental mediation, online activities, and cyberbullying. CyberPsychology \& Behavior, 12, 387-93.

Mitchell, K. J., Finkelhor, D., \& Wolak, J. (2005). Protecting youth online: Family use of filtering and blocking software. Child Abuse and Neglect, 29, 753-765. http://dx.doi.org/10.1016/j.chiabu.2004.05.008

Navarro, J. N., \& Jasinski, J. L. (2013). Why girls? Using routine activities theory to predict cyberbullying experiences between girls and boys. Women \& Criminal Justice, 23, 286-303.

http://dx.doi.org/10.1080/08974454.2013.784225

Olweus, D. (1978). Aggression in the schools: Bullies and whipping boys. Washington, DC: Hemisphere Press (Wiley).

Olweus, D., \& Limber, S. P. (2010). Bullying in school: Evaluation and dissemination of the Olweus bullying prevention program. American Journal of Orthopsychiatry, 80, 124-134.

http://dx.doi.org/10.1111/j.1939-0025.2010.01015.x

Patchin, J. W., \& Hinduja, S. (2010). Cyberbullying and self-esteem. Journal of School Health, 80, 614621. http://dx.doi.org/10.1111/j.1746-1561.2010.00548.x

Pomerantz, E. M., \& Ruble, D. N. (1998). The role of maternal control in the development of sex differences in child self-evaluative factors. Child Development, 69, 458-478.

http://dx.doi.org/10.1111/j.1467-8624.1998.tb06202.x

Prensky, M. (2001a). Digital natives, digital immigrants Part 1. On the Horizon, 9(5), 1-6.

Prensky, M. (2001b). Digital natives, digital immigrants Part 2. Do they really think differently? On the Horizon, 9(6), 1-6. 
Priebe, G., Mitchel, K., \& Finkelhor, D. (2013). To tell or not to tell: Youth's responses to unwanted internet experiences. Cyberpsychology: Journal of Psychosocial Research on Cyberspace, 7(1), article 6. http://dx.doi.org/10.5817/CP2013-1-6

Schneider, S. K., O'Donnell, L., Stueve, A., \& Coulter, R. W. S. (2012). Cyberbullying, school bullying, and psychological distress: a regional census of high school students. American Journal of Public Health, 102, 171-177. http://dx.doi.org/10.2105/AJPH.2011.300308

Schoffstall, C. L., \& Cohen, R. (2011). Cyber aggression: The relation between online offenders and offline social competence. Social Development, 20, 587-604. http://dx.doi.org/10.1111/j.1467-

9507.2011.00609.x

Seiler, S. J., \& Navarro, J. N. (2014). Bullying on the pixel playground: Investigating risk factors of cyberbullying at the intersection of children's online-offline social lives. Cyberpsychology: Journal of Psychoscoial Research on Cyberspace, 8(4), article 6. http://dx.doi.org/10.5817/CP2014-4-6

Smetana, J. G. (1988). Adolescents' and parents' conceptions of parental authority. Child Development, 59, 321-335. http://dx.doi.org/10.2307/1130313

Smetana, J. G., \& Asquith, P. (1994). Adolescents' and parents' conceptions of parental authority and personal autonomy. Child Development, 65, 1147-1162. http://dx.doi.org/10.2307/1131311

Stattin, H., \& Kerr, M. (2000). Parental monitoring: A reinterpretation. Child Development, 71, 10721085. http://dx.doi.org/10.1111/1467-8624.00210

Talves, K., \& Kalmus, V. (2015). Gendered mediation of children's internet use: A keyhole for looking into changing socialization practices. Cyberpsychology Journal of Psychosocial Research on Cyberspace, 9(1), article 4. http://dx.doi.org/10.5817/CP2015-1-4

Tilton-Weaver, L. C., Burk, W. J., Kerr, M., \& Stattin, H. (2013). Can parental monitoring and peer management reduce the selection or influence of delinquent peers? Testing the question using a dynamic social network approach. Developmental Psychology, 49, 2057-2070.

http://dx.doi.org/10.1037/a0031854

Tisak, M. (1986). Children's conceptions of parental authority. Child Development, 57, 166-176. http://dx.doi.org/10.2307/1130648

Tisak, M. (1995). Domains of social reasoning and beyond. Annals of Child Development, 11, 95-130. London: Jessica Kingsley.

Tisak, M. S., Tisak, J., \& Goldstein, S. E. (2006). Aggression, delinquency, and morality: A social-cognitive perspective. In M. Killen \& J. Smetana (Eds.), Handbook of moral development (pp. 611-629). Mahwah, NJ: LEA.

Turiel, E. (2006). The development of morality. In N. Eisenberg (Ed.), Handbook of child psychology: Vol. 3, Social, emotional, and personality development (6th ed., pp. 789-857). New York: Wiley.

Valles, N., \& Knutson, J. F. (2008). Contingent responses of mothers and peers to indirect and direct aggression is preschool and school-aged children. Aggressive Behavior, 34, 497-510.

http://dx.doi.org/10.1002/ab.20268

Werner, N. E., Bumpus, M. F., \& Rock, D. (2010). Involvement in internet aggression during early adolescence. Journal of Youth and Adolescence, 39, 607-619. http://dx.doi.org/10.1007/s10964-0099419-7

Werner, N. E., Senich, S., \& Przepyszny, K. A. (2006). Mothers' responses to preschoolers' relational and physical aggression. Applied Developmental Psychology, 27, 193-208.

http://dx.doi.org/10.1016/j.appdev.2006.02.002 
Wright, M. F. (2015). Cyber victimization and adjustment difficulties: The mediation of Chinese and American adolescents' digital technology use. Cyberpsychology: Journal of Psychosocial Research on Cyberspace, 9(1), article 7. http://dx.doi.org/10.5817/CP2015-1-7

Ybarra, M. L., boyd, d., Korchmaros, J. D., \& Oppenheim, J. (2012). Defining and measuring cyberbullying within the larger context of bullying victimization. Journal of Adolescent Health, 51, 53-58.

http://dx.doi.org/10.1016/j.jadohealth.2011.12.031

Ybarra, M. L., Finkelhor, D., Mitchell, K. J., \& Wolak, J. (2009). Associations between blocking, monitoring, and filtering software on the home computer and youth-reported unwanted exposure to sexual material online. Child Abuse and Neglect, 33, 857-869. http://dx.doi.org/10.1016/j.chiabu.2008.09.015

Ybarra, M. L., \& Mitchell, K. J. (2004). Youth engaging in online harassment: Associations with caregiverchild relationships, internet use, and personal characteristics. Journal of Adolescence, 27, 319-336.

http://dx.doi.org/10.1016/j.adolescence.2004.03.007

Zimmer-Gembeck, M. J., Ducat, W., \& Collins, W. A. (2011). Autonomy development during adolescence. In B. B. Brown \& M. Prinstein (Eds.), Encyclopedia of adolescence (pp. 66-76). New York: Academic Press. http://dx.doi.org/10.1016/B978-0-12-373951-3.00004-1

\section{Correspondence to:}

Dr. Sara E. Goldstein

Department of Family and Child Studies

Montclair State University

Montclair

NJ 07043

Email: goldsteins(at)mail.montclair.edu

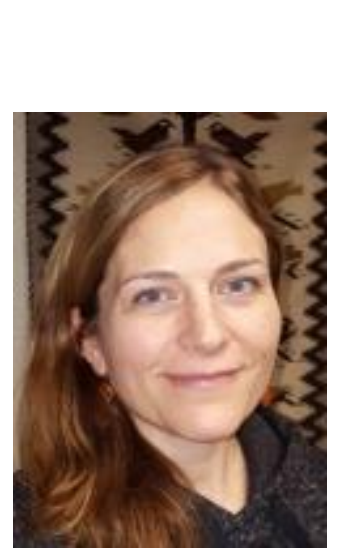

\section{About author}

Sara E. Goldstein, PhD is an Associate Professor of Family and Child Studies at Montclair State University in Montclair, New Jersey (USA). She earned her PhD from Bowling Green State University in Developmental Psychology, and completed a postdoctoral fellowship at the University of Michigan at the Institute for Research on Women and Gender. Her research focuses on social and social cognitive development during adolescence, with an emphasis on the development and implications of aggressive behavior in the context of peer and family relationships. 